\title{
Update on management options in the treatment of nosocomial and ventilator assisted pneumonia: review of actual guidelines and economic aspects of therapy
}

\author{
This article was published in the following Dove Press journal: \\ Infection and Drug Resistance \\ 18 December 2013 \\ Number of times this article has been viewed
}

\author{
Michael Wilke' \\ Rolf Grube' \\ 'Dr. Wilke GmbH, Munich, Germany
}

\begin{abstract}
Objective: Nosocomial or more exactly, hospital-acquired (HAP) and ventilator-associated pneumonia (VAP) are frequent conditions when treating intensive care unit (ICU) patients that are only exceeded by central line-associated bloodstream infections. In Germany, approximately 18,900 patients per year suffer from a VAP and another 4,200 from HAP. We therefore reviewed the current guidelines about HAP and VAP, from different sources, regarding the strategies to address individual patient risks and medication strategies for initial intravenous antibiotic treatment (IIAT).
\end{abstract}

Material and methods: We conducted an analysis of the recent guidelines for the treatment of HAP. The current guidelines of the American Thoracic Society, the treatment recommendations of the Paul-Ehrlich-Gesellschaft (PEG), the guidelines from the British Society for Antimicrobial Chemotherapy, the VAP guideline of the Canadian Critical Care trials group, as well as the new German S3-guideline for HAP were examined.

Results: All guidelines are based on grading systems that assess the evidence underlying the recommendations. However, each guideline uses different grading systems. One common aspect of these guidelines is the risk assessment of the patients for decision making regarding IIAT. Most guidelines have different recommendations depending on the risk of the presence of multidrug resistant (MDR) bacteria. In guidelines using risk assessment, for low-risk patients (early onset, no MDR risk) aminopenicillins with beta-lactamase inhibitors (BLI), second or third generation cephalosporins, quinolones, or ertapenem are recommended. For patients with higher risk, imipenem, meropenem, fourth generation cephalosporins, ceftazidime or piperacillin/tazobactam are recommended. The PEG recommendations include a combination therapy in cases of very high risk (late onset, MDR risk, ICU, and organ failure) of either piperacillin/tazobactam, dori-, imi- or meropenem or cefepime or ceftazidime with ciprofloxacin, levofloxacin, fosfomycin or an aminoglycoside. For the treatment of HAP caused by methicillin-resistant Staphylococcus aureus (MRSA), either linezolid or vancomycin is recommended. With regard to the ZEPHyR-trial, linezolid has shown higher cure rates but, no difference in overall survival. Economic analyses show the relevance of guideline-adherent IIAT (GA-IIAT). Besides significantly better clinical outcomes, patients with GA-IIAT cause significantly lower costs ( $€ 28,033$ versus (vs) $€ 36,139)$ $(P=0.006)$ and have a shorter length of stay in hospital ( 23.9 vs 28.3 days) $(P=0.022)$.

Conclusion: We conclude that most current treatment guidelines take into account the individual patient risk and that the correct choice of IIAT affects clinical as well as economical outcomes. Keywords: nosocomial pneumonia, ventilator, assoc. pneumonia, antibiotics, guidelines, review
Correspondence: Michael Wilke

Dr Wilke GmbH, Josep-Wild-Str I3,

D-8I829 München, Germany

Tel +4989 I890 83760

Fax +4989 $18908376-9$

Email michael.wilke@d-w-g.de submit your manuscript $\mid$ www.dovepress.com

Dovepress

http://dx.doi.org// 0.2/47/IDR.S25985
Infection and Drug Resistance 20 I4:7 I-7 I

(c) (1) (5) 2014 Wilke and Grube. This work is published by Dove Medical Press Limited, and licensed under Creative Commons Attribution - Non Commercial (unported, v3.0) License. The full terms of the license are available at http:///creativecommons.org/licenses/by-nc/3.0/. Non-commercial uses of the work are permitted without any further permission from Dove Medical Press Limited, provided the work is properly attributed. Permissions beyond the scope of the License are administered by Dove Medical Press Limited. Information on
how to request permission may be found at: http://www.dovepress.com/permissions.php 
Table I Synopsis of grading systems used in the respective guidelines

\begin{tabular}{ll}
\hline Grading & \\
\hline ATS & Evidence comes from well-conducted, randomized, controlled trials \\
Level I (high) & Evidence comes from well-designed, controlled trials without randomization (including cohort, patient series, and case- \\
Level II (moderate) & $\begin{array}{l}\text { control studies). Level II studies also include any large case series in which systematic analysis of disease patterns and/or } \\
\text { microbial etiology was conducted, as well as reports of new therapies that were not collected in a randomized fashion } \\
\text { Evidence comes from case studies and expert opinion. In some instances, therapy recommendations come } \\
\text { from antibiotic susceptibility data without clinical observations }\end{array}$
\end{tabular}

A

At least one meta-analysis, systematic review, or RCT rated as I++ and directly applicable to the target population; or a body of evidence consisting principally of studies rated as I+, directly applicable to the target population, and demonstrating overall consistency of results

A body of evidence including studies rated as $2++$, directly applicable to the target populat
overall consistency of results; or extrapolated evidence from studies rated as I++ or I+

C A body of evidence including studies rated as 2+, directly applicable to the target population and demonstrating overall consistency of results; or extrapolated evidence from studies rated as $2++$

D Evidence level 3 or 4; or extrapolated evidence from studies rated as 2+

\section{Good clinical practice points}

Recommended best practice based on the clinical experience of the guideline development group

$\mathrm{I}+\mathrm{H}$

$1+$

$1-$

2++

$2+$

2-

3

4

\section{CCCTG}

Level I

Level 2

Level 3

Recommend

Consider

No recommendation

Do not recommend

\section{G-HAP}

IA

IB

IC

$2 \mathrm{~A}$

$2 B$

$2 \mathrm{C}$

3

PEG

A

A

B

B

B

C

Abbreviations: ATS, American Thoracic Society; BSAC, British Society for Antimicrobial Chemotherapy; CCCTG, Canadian Critical Care Trials Group; G-HAP, S3Guideline for hospital acquired pneumonia in Germany; PEG, Paul-Ehrlich-Gesellschaft; RCT, randomized, controlled trial; VAP, ventilator-associated pneumonia.

High-quality meta-analyses, systematic reviews of RCTs, or RCTs with a very low risk of bias

Well-conducted meta-analyses, systematic reviews, or RCTs with a low risk of bias

Meta-analyses, systematic reviews, or RCTs with a high risk of bias

High-quality systematic reviews of case control or cohort studies. High-quality case-control or cohort studies

with a very low risk of confounding or bias and a high probability that the relationship is causal

Well-conducted case control or cohort studies with a low risk of confounding or bias and a moderate

probability that the relationship is causal

Case-control or cohort studies with a high risk of confounding or bias and a significant risk that the

relationship is not causal

Nonanalytic studies, eg, case reports, case series

Expert opinion

Randomized, controlled trials, blinded-outcome adjudication, intention-to-treat-analysis, explicit definition of VAP

Any condition mentioned above unfulfilled

No randomization

" $\ldots$ if there were no reservations about endorsing an intervention."

" $\ldots$ if the evidence supported an intervention but there were minor uncertainties about the benefits, harms, or costs."

“... was made if evidence regarding an intervention was inadequate or if there were major uncertainties about the benefits, harms, and costs."

" $\ldots$ if there was no evidence of benefit and there was potential for harm or increased healthcare costs from the intervention."

Strong recommendation, high evidence - desirable effects clearly outweigh risks or additional resource

consumption or vice versa

Strong recommendation, moderate evidence

Strong recommendation, low or very low evidence

Weak recommendation, high evidence - desirable effects possibly outweigh risks or additional resource

consumption or vice versa

Weak recommendation, moderate evidence

Weak recommendation, low or very low evidence

No recommendation - no clear indication for presence of benefit or risk

la evidence based on meta-analyses of RCT

lb evidence based on at least one RCT

Ila evidence based on at least one well-designed controlled study without randomization

Ilb evidence based on at least one well-designed quasi-experimental study

III evidence based on well-designed nonexperimental studies (eg, case-control study)

IV evidence based on expert opinions, results of consensus/conferences 


\section{Introduction}

When treating intensive care unit (ICU) patients, nosocomial infection or more exactly, hospital acquired pneumonia (HAP) and ventilator-associated pneumonia (VAP) are frequent conditions only exceeded by central line-associated bloodstream infections. ${ }^{1}$ The epidemiologic data about HAP and VAP are associated with a relatively high level of uncertainty because of varying definitions and methodologies.

In Germany, according to data from the hospital infection surveillance system, [Krankenhaus-Infektions-SurveillanceSystem (KISS)], approximately 18,900 patients in an ICU per year suffer from a VAP, and another 4,200 suffer from HAP without being mechanically ventilated. ${ }^{2,3}$ In contrast, based on a query from the Federal Statistical Office, in 2011, HAP was coded in 103,040 cases in Germany (Statistisches Bundesamt, email communication, April, 2013).

In the United States, approximately five to ten HAP episodes per 1,000 hospital admissions occur ${ }^{4}$ or about 200 to 400 thousand HAP episodes per year, according to admission statistics from the US. ${ }^{5}$

The objective of this review paper was to give an overview of the current therapy guidelines for the treatment of HAP/ VAP and to summarize the most common recommendations, to provide useful and practical information for clinical decision making. Moreover, the economic consequences of guideline-adherent initial intravenous antibiotic therapy (GA-IIAT) versus (vs) non-GA-IIAT was also examined.

\section{Materials and methods}

The current guidelines of the American Thoracic Society (ATS) ${ }^{4}$ and the British Society for Antimicrobial Chemotherapy (BSAC), ${ }^{6}$ the VAP guideline of the Canadian Critical Care trials group (CCCTG), ${ }^{7}$ as well as the new S3-guideline for HAP in Germany were included in this review. ${ }^{8}$ In addition, the treatment recommendations published by the PaulEhrlich-Gesellschaft (PEG) were reviewed as well. ${ }^{9,10}$

All guidelines were examined under the following criteria:

- Which system was used to grade the underlying evidence?

- Does the guideline contain risk assessment addressing the presence of complicated pathogens?

- Which treatment recommendations are given for initial intravenous antibiotic therapy (IIAT)?

We retrieved the original texts of all the guidelines as well as the level of evidence for each recommendation. Next we examined the guidelines as described above. We then summarized the results in tables, attempting to summarize the most common recommendations as well as their level of evidence. Finally we conducted a search for papers that examine the economic consequences of treatment in HAP, and these were reviewed.

\section{Results}

One common aspect of the guidelines we reviewed is the risk assessment of patients designed to guide decision making regarding the IIAT. All the guidelines use a system of risk assessment to determine the presence of bacteria that require special coverage when determining IIAT.

The reviewed guidelines differ in several aspects. The CCCTG guideline focuses on VAP, while the German guideline as well as the BSAC guideline and the PEG recommendation cover both HAP and VAP. The ATS guideline additionally discusses the newly introduced concept of health-care associated pneumonia (HCAP), as a third class of nosocomial pneumonias.

All guidelines use different approaches and terminology to measure evidence. The different systems are shown in Table 1. The effects of these differences are demonstrated by the recommendations about the duration of antibiotic therapy. The PEG recommends duration of $3-5$ days after good clinical improvement, but not more than 10-14 days (grade C, BSAC, see Table 1). The ATS guideline recommends shortening the duration from 14-21 to 7 days in the absence of Pseudomonas aeruginosa and when the patient has had a good clinical response (level 1). The BSAC and the Canadian guideline recommend a maximum of 8 days in responding patients (BSAC: grade C; CCCTG: recommend). The German guideline gives a strong recommendation (grade A) for the duration of 8 days in regular cases (Table 1).

Except for the CCCTG guideline, all the guidelines make use of risk stratification to a greater or lesser extent. The PEG recommendation uses a scoring system to allocate patients to groups based upon the Complicated Pathogen Risk assessment Score (CPRS). ${ }^{9}$ Based on the CPRS, groups of antibiotics are recommended to be used until the pathogens are identified

Table 2 Score for risk factors influencing antibiotic strategy according to the PEG recommendation

\begin{tabular}{ll}
\hline Risk factor & Points \\
\hline Age $>65$ years & 1 \\
Preexisting structural lung disease & 2 \\
Recent antibiotic therapy & 2 \\
Late onset $>4$ days in hospital & 3 \\
Severe respiratory insufficiency with/without mechanical & 3 \\
ventilation & \\
Extrapulmonary organ failure & 4 \\
\hline
\end{tabular}

Abbreviation: PEG, Paul-Ehrlich-Gesellschaft. 
by microbiological methods (Table 2). The pharmacological strategies for the IIAT are summarized in Table 3.

The topic of prevention is discussed in the ATS guideline, the $\mathrm{PEG}$ recommendation, as well as in the $\mathrm{BSAC}$ guideline but not in the German or the CCCTG guideline. The CCCTG published a separate guideline about VAP prevention. ${ }^{11}$
Table 3 provides an overview of the therapy recommendations for IIAT (where included in the guideline). The table shows that the guidelines examined have substantial differences in risk assessment. The PEG recommendations provide - using the CPRS - the most straightforward decision making process, which is easy to use in clinical practice.

Table 3 Overview of recommendations from all examined guidelines

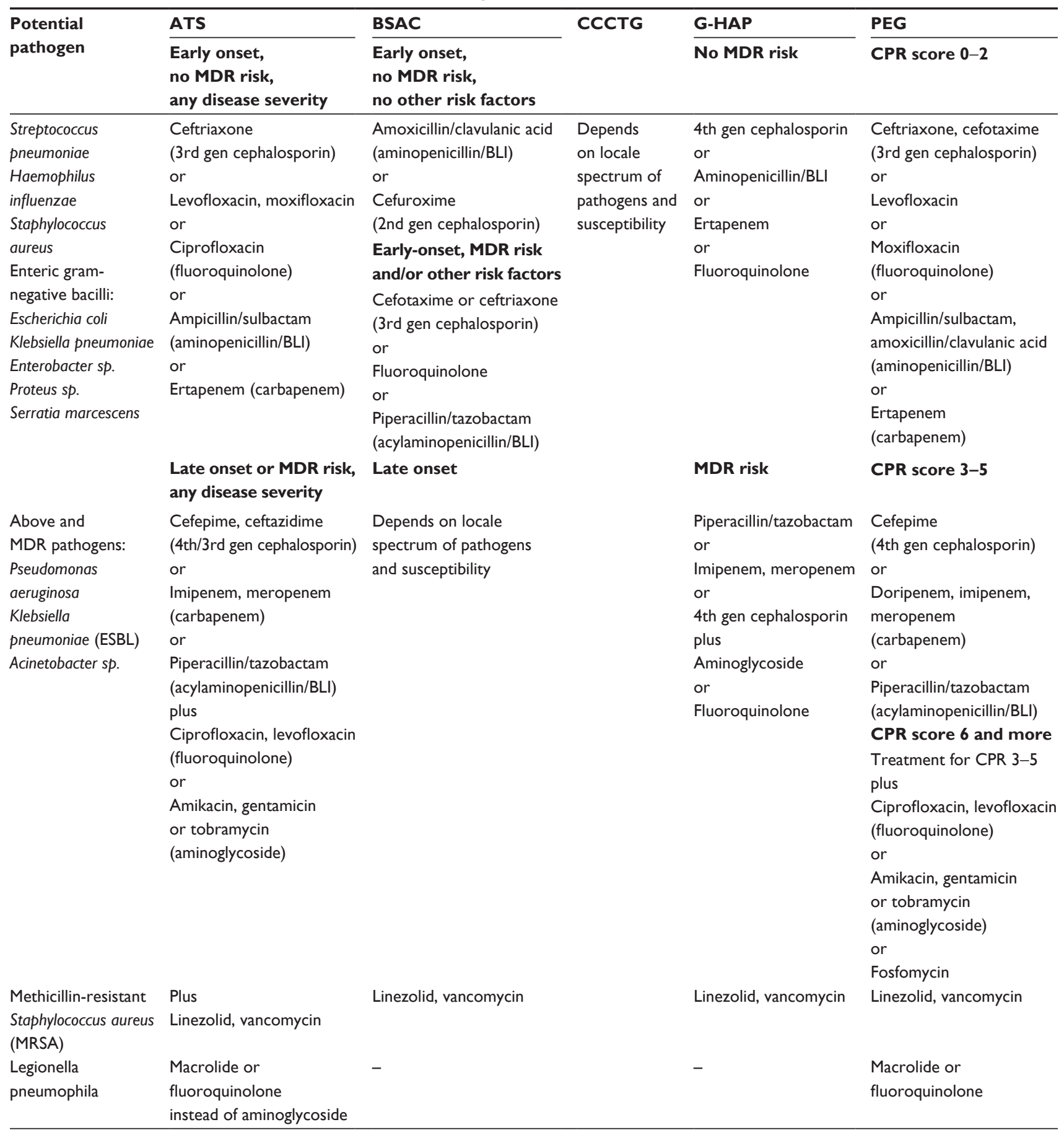

Abbreviations: ATS, American Thoracic Society; BLI, beta-lactamase inhibitor; BSAC, British Society for Antimicrobial Chemotherapy; CCCTG, Canadian Critical Care Trials Group; CPR, clinical patient risk score; G-HAP, S3-Guideline for hospital-acquired pneumonia in Germany; gen, generation; MDR, multidrug resistance; PEG, PaulEhrlich-Gesellschaft; ESBL, extended-spectrum beta-lactamase. 
For better comparability, we have defined the following classes for assessing the risk of complicated pathogens:

- No multidrug resistance (MDR) risk (early onset of pneumonia, no prior antibiotic therapy, no VAP, no comorbidities, and no other organ failure)

- Medium MDR risk (prior antibiotic therapy, late onset, and comorbidities)

- High MDR risk (late onset, VAP, prior antibiotic therapy, comorbidities, and organ failures)

Table 4 shows the most commonly given recommendations for treatment and the frequency with which the therapy is recommended in a guideline.

\section{Discussion}

Together, HAP and VAP are the second most reason of nosocomial infection and a substantial risk for

Table 4 Most common recommendations risk-adjusted

\begin{tabular}{|c|c|c|}
\hline Risk category & $\begin{array}{l}\text { Antibiotic therapy } \\
\text { recommended }\end{array}$ & $\begin{array}{l}\text { Recommended } \\
\text { in how many } \\
\text { guidelines }(n=5)\end{array}$ \\
\hline \multirow{6}{*}{$\begin{array}{l}\text { No MDR risk } \\
\text { (early onset, } \\
\text { no prior antibiotic } \\
\text { therapy, no VAP, } \\
\text { no comorbidities, } \\
\text { no other organ } \\
\text { failure) }\end{array}$} & $\begin{array}{l}\text { 2nd gen cephalosporin } \\
\text { (eg, cefuroxime) }\end{array}$ & 2 \\
\hline & $\begin{array}{l}\text { 3rd gen cephalosporin } \\
\text { (eg, ceftriaxone) }\end{array}$ & 3 \\
\hline & $\begin{array}{l}\text { 4th gen cephalosporin } \\
\text { (cefepime) }\end{array}$ & 1 \\
\hline & $\begin{array}{l}\text { Aminopenicillin/BLI (eg, } \\
\text { amoxicillin/clavulanic acid) }\end{array}$ & 4 \\
\hline & $\begin{array}{l}\text { Quinolones } \\
\text { (eg, levofloxacin) }\end{array}$ & 3 \\
\hline & Ertapenem & 3 \\
\hline \multirow{7}{*}{$\begin{array}{l}\text { Medium MDR risk } \\
\text { (prior antibiotic } \\
\text { therapy, late onset, } \\
\text { comorbidities) }\end{array}$} & $\begin{array}{l}\text { 3rd gen cephalosporin } \\
\text { (eg, ceftriaxone) }\end{array}$ & 2 \\
\hline & $\begin{array}{l}\text { 4th gen cephalosporin } \\
\text { (cefepime) }\end{array}$ & 4 \\
\hline & $\begin{array}{l}\text { Acylaminopenicillin/BLI } \\
\text { (eg, piperacillin/tazobactam) }\end{array}$ & 4 \\
\hline & Doripenem & 1 \\
\hline & Imipenem & 3 \\
\hline & Meropenem & 3 \\
\hline & Quinolones (eg, levofloxacin) & 1 \\
\hline \multirow{6}{*}{$\begin{array}{l}\text { High MDR risk (late } \\
\text { onset, VAP, prior } \\
\text { antibiotic therapy, } \\
\text { comorbidities, } \\
\text { eventual organ } \\
\text { failures) }\end{array}$} & All substances of medium & 3 \\
\hline & MDR-risk & \\
\hline & Plus combination of & \\
\hline & $\begin{array}{l}\text { Quinolones (eg, levofloxacin) } \\
\text { or }\end{array}$ & 3 \\
\hline & $\begin{array}{l}\text { Aminoglycosides } \\
\text { or }\end{array}$ & 3 \\
\hline & Fosfomycin & I \\
\hline \multirow[t]{2}{*}{ Risk of MRSA } & Vancomycin & 4 \\
\hline & Linezolid & 4 \\
\hline
\end{tabular}

Abbreviations: BLI, beta-lactamase inhibitor; gen, generation: MDR, multidrug resistance; MRSA, methicillin-resistant Staphylococcus aureus; VAP, ventilatorassociated pneumonia. hospitalized patients. Barbier et al showed, not only a rate up to 16 episodes per 1,000 ventilator days but also, attributable mortality of $3 \%-17 \% .{ }^{12}$ In a retrospective matched cohort study comparing patients with VAP with patients without VAP, Kollef et al reported prolonged ventilation episodes (21.8 vs 10.3 days), ICU stay (20.5 vs 11.6 days), and hospital stay (32.6 vs 19.5 days), but a significantly lower mortality $(22.5 \%$ vs $29.4 \%) .{ }^{13}$ The authors of the present article reported results of a retrospective study of HAP from five German tertiary care hospitals $;{ }^{14}$ in that study, the overall mortality of patients with HAP was $20.3 \%$.

It can accordingly be concluded that adequate preventive, diagnostic and therapeutic measures can improve, not only economic outcome parameters but also, the clinical outcome of patients.

Comparing the details of the guidelines was difficult due to the different grading systems used. These different approaches clearly affect the quality of guidelines, as shown by Atkins et a $1^{15}$ as well as Aarts et al. ${ }^{16}$

The treatment of HAP is also an economic challenge for hospitals, especially in countries where payment is dependent on diagnosis-related groups (DRGs). Kollef et al reported the excess costs of VAP cases compared with ventilated patients who do not acquire VAP to be US $\$ 39,828,{ }^{13}$ while Moller et al showed that the costs to prevent a VAP episode are only $€ 4,451 .{ }^{17}$ Thompson et $\mathrm{al}^{18}$ found a significant difference in mortality $(10.7 \%$ vs $1.2 \%[P<0.001])$ when HAP occurred after abdominal surgery. The mean length of stay (LOS) for patients who developed HAP after intra-abdominal surgery was significantly greater compared with patients who did not develop HAP after intra-abdominal surgery (17.10 days vs 6.07 days $)(P<0.001)$. After adjusting for patient characteristics, HAP was independently associated with a $75 \%$ mean increase in total hospital charges (US $\$ 28,160.95$; 95\% confidence interval: US\$27,543.76-US\$28,778.13).

Only very few analyses have examined the impact of the correct IIAT on clinical and economic outcomes. Piskin et al reported a significantly longer hospital LOS for patients receiving inadequate antibiotic therapy compared with patients receiving adequate antibiotic therapy (for HAP, this was +4.6 days $[P=0.001]$; for VAP, this was +16.4 days $[P=0.009]) .{ }^{19}$ Inadequate IIAT was also shown to cause besides worse clinical outcomes - the additional costs of $€ 8,106(P=0.006)$ and a prolongation of LOS of 4.5 days $(P=0.022)$ in a retrospective analysis undertaken by the authors of the present article. ${ }^{14}$ In contrast, Kett et al designed a prospective observational multicenter study for VAP possibly caused by MDR pathogens. Their results showed a 
higher mortality of patients in the guideline-compliant group (34\%) compared with the noncompliant group $(20 \%)^{20}$ even when the models were adjusted for covariates. The authors do not exclude the possibility of unobserved factors that may influence mortality. Becher et al compared the effect of use of locally adjusted guidelines for HAP with the use of the ATS guideline, in retrospective data, and found better coverage of resistance with the local guideline. ${ }^{21}$ These findings clearly show that further research on guideline outcomes is necessary.

\section{Conclusion}

Most guidelines recommend an IIAT according to the individually assessed risk. For uncomplicated cases, the combination of aminopenicillins plus a beta-lactamase inhibitor (BLI) is most frequently mentioned as a first-line therapy option, followed by third generation cephalosporins, quinolones, and ertapenem.

For more complicated cases, the use of acylaminopenicillins/BLI (eg, piperacillin/tazobactam), followed by imiand meropenem and fourth generation cephalosporins is recommended.

In the group of most complicated cases, three guidelines recommend a combination therapy of acylaminopenicillins/ BLI (eg, piperacillin/tazobactam), followed by imi- and meropenem and fourth generation cephalosporins plus quinolones, aminoglycosides, or fosfomycin.

If there is a risk of methicillin-resistant Staphylococcus aureus (MRSA), all the guidelines recommend vancomycin or linezolid. Due to recent trial results, linezolid is recognized to have better cure rates, but the 60-day mortality was similar in both groups. ${ }^{21}$

We conclude that the current treatment guidelines take into account the individual patient risk, and the correct choice of IIAT affects clinical as well as economical outcomes.

\section{Disclosure}

The authors disclose the following possible conflicts of interests: RG and MW received research grants and honoraria for lectures from Pfizer Pharma GmbH, Germany. Until 2010, MW received honoraria for lectures from Wyeth Pharma GmbH, Germany. The authors report no other conflicts of interest in this work.

\section{References}

1. Rosenthal VD, Maki DG, Jamulitrat S, et al; INICC Members. International Nosocomial Infection Control Consortium (INICC) report, data summary for 2003-2008, issued June 2009. Am J Infect Control. 2010;38(2):95-104. e2.
2. Kohlenberg A, Schwab F, Behnke M, Geffers C, Gastmeier P. Pneumonia associated with invasive and noninvasive ventilation: an analysis of the German nosocomial infection surveillance system database. Intensive Care Med. 2010;36(6):971-978.

3. Geffers $C$, Gastmeier P. Nosocomial infections and multidrug-resistant organisms in Germany: epidemiological data from KISS (the Hospital Infection Surveillance System). Dtsch Arztebl Int. 2011;108(6): 87-93.

4. American Thoracic Society; Infectious Diseases Society of America. Guidelines for the management of adults with hospital-acquired, ventilator-associated, and healthcare-associated pneumonia. Am J Respir Crit Care Med. 2005;171(4):388-416.

5. American Hospital Association. Fast Facts on US Hospitals. Chicago, IL: Health Forum LLC; 2013. Available from: http://www.aha.org/ research/rc/stat-studies/fast-facts.shtml. Accessed October 5, 2013.

6. Masterton RG, Galloway A, French G, et al. Guidelines for the management of hospital-acquired pneumonia in the UK: report of the working party on hospital-acquired pneumonia of the British Society for Antimicrobial Chemotherapy. JAntimicrob Chemother. 2008;62(1): $5-34$.

7. Muscedere J, Dodek P, Keenan S, Fowler R, Cook D, Heyland D; VAP Guidelines Committee and the Canadian Critical Care Trials Group. Comprehensive evidence-based clinical practice guidelines for ventilator-associated pneumonia: diagnosis and treatment. J Crit Care. 2008;23(1):138-147.

8. Dalhoff K, Abele-Horn M, Andreas S, et al. [Epidemiology, diagnosis and treatment of adult patients with nosocomial pneumonia. S-3 Guideline of the German Society for Anaesthesiology and Intensive Care Medicine, the German Society for Infectious Diseases, the German Society for Hygiene and Microbiology, the German Respiratory Society and the Paul-Ehrlich-Society for Chemotherapy]. Pneumologie. 2012;66(12):707-765. German.

9. Lorenz J, Bodmann KF, Bauer TT, Ewig S, Trautmann M, Vogel F; German Society for Anesthesiology and Intensive Care (DGAI). [Nosocomial pneumonia: prevention, diagnosis, treatment]. Pneumologie. 2003;57(9):532-545. German.

10. Bodmann KF, Grabein B; Expertenkommission der Paul-ErlichGesellschaft für Chemotherapie eV. Empfehlungen zur kalkulierten parenteralen initialtherapie bakterieller er-krankungen bei erwachsenen: Update 2010. Chemother $J$ [serial on the Internet]. 2010 [cited 2013 Aug 15];19(6):179-255. http://www.chemotherapie-journal.de/archiv/ artikel/2010/06/186.html. Accessed October 5, 2013.

11. Muscedere J, Dodek P, Keenan S, Fowler R, Cook D, Heyland D; VAP Guidelines Committee and the Canadian Critical Care Trials Group. Comprehensive evidence-based clinical practice guidelines for ventilator-associated pneumonia: prevention. J Crit Care. 2008;23(1): 126-137.

12. Barbier F, Andremont A, Wolff M, Bouadma L. Hospital-acquired pneumonia and ventilator-associated pneumonia: recent advances in epidemiology and management. Curr Opin Pulm Med. 2013;19(3): 216-228.

13. Kollef MH, Hamilton CW, Ernst FR. Economic impact of ventilatorassociated pneumonia in a large matched cohort. Infect Control Hosp Epidemiol. 2012;33(3):250-256.

14. Wilke M, Grube RF, Bodmann KF. Guideline-adherent initial intravenous antibiotic therapy for hospital-acquired/ventilator-associated pneumonia is clinically superior, saves lives and is cheaper than non guideline adherent therapy. Eur J Med Res. 2011;16(7): 315-323.

15. Atkins D, Eccles M, Flottorp S, et al; GRADE Working Group. Systems for grading the quality of evidence and the strength of recommendations I: critical appraisal of existing approaches The GRADE Working Group. BMC Health Serv Res. 2004;4(1):38.

16. Aarts MC, van der Heijden GJ, Rovers MM, Grolman W. Remarkable differences between three evidence-based guidelines on management of obstructive sleep apnea-hypopnea syndrome. Laryngoscope. 2013;123(1):283-291. 
17. Møller AH, Hansen L, Jensen MS, Ehlers LH. A cost-effectiveness analysis of reducing ventilator-associated pneumonia at a Danish ICU with ventilator bundle. J Med Econ. 2012;15(2):285-292.

18. Thompson DA, Makary MA, Dorman, T et al. Clinical and Economic Outcomes of Hospital Acquired Pneumonia in Intra-Abdominal Surgery Patients. Ann Surg. 2006;243(4): 547-552. Available from: http://www. ncbi.nlm.nih.gov/pmc/articles/PMC1448956/. Accessed November 2, 2013.

19. Piskin N, Aydemir H, Oztoprak N, et al. Inadequate treatment of ventilator-associated and hospital-acquired pneumonia: risk factors and impact on outcomes. BMC Infect Dis. 2012;12:268.
20. Kett DH, Cano E, Quartin AA, et al; Improving Medicine through Pathway Assessment of Critical Therapy of Hospital-Acquired Pneumonia (IMPACT-HAP) Investigators. Implementation of guidelines for management of possible multidrug-resistant pneumonia in intensive care: an observational, multicentre cohort study. Lancet Infect Dis. 2011;11(3):181-189.

21. Becher RD, Hoth JJ, Rebo JJ, Kendall JL, Miller PR. Locally derived versus guideline-based approach to treatment of hospital-acquired pneumonia in the trauma intensive care unit. Surg Infect (Larchmt). 2012;13(6):352-359.

\section{Publish your work in this journal}

Infection and Drug Resistance is an international, peer-reviewed openaccess journal that focuses on the optimal treatment of infection (bacterial, fungal and viral) and the development and institution of preventive strategies to minimize the development and spread of resistance. The journal is specifically concerned with the epidemiology of antibiotic

\section{Dovepress}

resistance and the mechanisms of resistance development and diffusion in both hospitals and the community. The manuscript management system is completely online and includes a very quick and fair peerreview system, which is all easy to use. Visit http://www.dovepress.com/ testimonials.php to read real quotes from published authors.

Submit your manuscript here: http://www.dovepress.com/infection-and-drug-resistance-journal 